\title{
Age-related changes in subjective cognitive functioning.
}

Citation for published version (APA):

Ponds, R. W. H. M., van Boxtel, M. P. J., \& Jolles, J. (2000). Age-related changes in subjective cognitive functioning. Educational Gerontology, 26(1), 67-81. https://doi.org/10.1080/036012700267402

Document status and date:

Published: 01/01/2000

DOI:

10.1080/036012700267402

Document Version:

Publisher's PDF, also known as Version of record

\section{Please check the document version of this publication:}

- A submitted manuscript is the version of the article upon submission and before peer-review. There can be important differences between the submitted version and the official published version of record.

People interested in the research are advised to contact the author for the final version of the publication, or visit the DOI to the publisher's website.

- The final author version and the galley proof are versions of the publication after peer review.

- The final published version features the final layout of the paper including the volume, issue and page numbers.

Link to publication

\footnotetext{
General rights rights.

- You may freely distribute the URL identifying the publication in the public portal. please follow below link for the End User Agreement:

www.umlib.nl/taverne-license

Take down policy

If you believe that this document breaches copyright please contact us at:

repository@maastrichtuniversity.nl

providing details and we will investigate your claim.
}

Copyright and moral rights for the publications made accessible in the public portal are retained by the authors and/or other copyright owners and it is a condition of accessing publications that users recognise and abide by the legal requirements associated with these

- Users may download and print one copy of any publication from the public portal for the purpose of private study or research.

- You may not further distribute the material or use it for any profit-making activity or commercial gain

If the publication is distributed under the terms of Article $25 \mathrm{fa}$ of the Dutch Copyright Act, indicated by the "Taverne" license above, 

FUNCTIONING

\author{
Rudolf W. H. M. Ponds \\ M. P. J. van Boxtel \\ Jellemer Jolles \\ Maastricht Brain and Behaviour Institute, \\ Department of Psychiatry and Neuropsychology, \\ Maastricht University, the Netherlands
}

\begin{abstract}
The main focus of this study was to examine age-related changes in self-evaluation of cognitive functioning in the domains of memory, attention, mental speed, planning, and decision making. Almost 2,000 persons in the age range 24 to 86 years rated their present cognitive functioning relative to three different reference points: compared to their age-mates, to their level 5 to 10 years ago, and to their level when they were 25 years. An age-stratified group of 420 participants also completed a series of cognitive tests. Age-related decline in subjective cognitive functioning started at the age of 50 and steadily increased afterward. This decline was not restricted to memory, but also involved changes in attention, mental speed, planning and decision making. When participants compared their present cognitive functioning with that of their own age-group, no age effects were found. Subjective health and depression were both related to subjective decline in cognitive functioning. No relation was found between subjective and objective cognitive functioning.
\end{abstract}

Studies on the self-appraisal of memory in the aged population have almost consistently shown that aging is accompanied by a subjective decline in daily memory functioning (e.g., Cutler \& Grams, 1988). There is, however, no straightforward relation between self-reported memory functioning and memory performance. Correlations between

Address correspondence to Rudolf W. H. M. Ponds, Maastricht Brain and Behaviour Institute, c/o University Hospital Maastricht, Department of Psychiatry (SPSY), P.O. Box 6800,6202 AZ Maastricht, the Netherlands. E-mail: rudolf.ponds@spsy.azm.nl 
subjective memory functioning, as measured with . .f-report questionnaires, and performance on memory tests are either absent or at best modest (Gilewski \& Zelinski, 1986). Yet, information on subjecive memory functioning in aged people is of considerable importance. Although self-perceptions of memory functioning may not be veridicial estimates of actual memory skills or competence, these perceptions may have a substantial impact on the behavior of elderly people in everyday memory demanding situations (Lovelace, 1990).

When reviewing the research on subjective cognitive functioning in the aged population, several shortcomings may be pointed out. The question whether the subjective age-related changes in cognition are global or specific cannot be answered because most studies are focused on memory only. Although a decline in memory functioning is probably the most prominent change when one grows older, other cognitive functions such as attention or problem-solving are also vulnerable to aging. It would therefore be of interest to examine to what extent older subjects experience subjective decline in these other cog. nitive functions as well.

The finding that memory complaints or incidents of memory failure are more frequent among elderly subjects is typically found in studies where a young sample is compared with an old sample. Only few studies have examined changes in subjective cognitive functioning over the whole adult age range, which is necessary to answer questions concerning the age at which changes occur, and the speed at which they proceed. Several studies have shown that people already start to notice a decline in memory functioning in their early middle age and that this decline steadily increases in the following years (Hulicka, 1982; Hultsch, Hertzog, \& Dixon, 1987).

The reference point to which people compare their present memory functioning is also of considerable importance. Relative measures of reported memory abilities, where people judge their present memory performance relative to some defined point in their own past performance, seem to yield more information than absolute measures, in which people have to judge their present functioning in either terms of a global rating (from "good" to "bad") or present frequency of welldescribed memory failures. Rabbitt (1982), for example, asked subjects to complete a memory questionnaire twice, reporting their current level of memory functioning and their level when they were 30 years old. No correlation was found between two list learning tasks and the present level of reported memory abilities, whereas the correlations between the memory tests and the difference scores between the two levels were substantial. In the same line are the findings of Hultsch et al. (1987) with the Metamemory in Adulthood questionnaire: strong 
age effect ere found on a scale in which subjects rate self-perceived decline in memory, whereas the age effects on a scale in which subjects rate their present memory capacity were rather small. Moreover, studies that showed no, or only small age-related differences in subjective memory functioning all used absolute instead of relative measures of memory (Cavanaugh, 1987; Chaffin \& Herrmann, 1983; Crook \& Larrabee, 1990; Jackson, Bogers, \& Kerstholt, 1988; McMillan, 1984).

In this article we report on the results of a study in which we examined self-report of cognitive functioning in the domains of memory, attention, mental speed, planning, and decision making. Almost 2,000 persons in the age range 24 to 86 years rated their present functioning relative to three reference points: to age-mates, to their level 5 to 10 years ago, and to their level when they were 25 years old. The primary research questions concerned the specificity of the subjective age-related decline in cognition and the age at which the first decline in cognitive functioning is noticed. We were also interested in the association between subjective cognitive functioning on the one hand and self-ratirg of depression and health on the other, as several studies have demonstrated a relation between self-appraisal of memory functioning and affective state (e.g., Bolla, Lindgren, Bonaccorsy, \& Bleecker, 1991) and self-appraisal and health (e.g., Cutler \& Grams, 1988). Finally, we looked at the relation between subjective and objective cognitive functioning in an agestratified subsample of 420 subjects aged 25 to 80 years.

\section{METHOD}

\section{Participants and Procedure}

This study was conducted as part of a large cross-sectional study into biological and psychological determinants of successful and pathological cognitive aging, which was part of a large research program on cognitive aging (Maastricht Aging Study-MAAS: Jolles; Houx, van Boxtel \& Ponds, 1995). In the first phase of this cross-sectional study an extensive postal questionnaire on subjective cognitive functioning in relation to age, health, and psychological factors was sent to 2,340 subjects aged 24 to 86 years.

Participants were recruited from a register of patients of general practices in the region of Maastricht in the Netherlands (Metsemakers, Höppener, Knottnerus, Kocken, \& Limonard, 1992). This register contains all relevant past and current medical morbidity 
as documented by the general practitioners. Subjects ih previous or actual medical conditions with known impact on cognitive or motor functions were excluded from the selection. Exclusion criteria were overt cerebrovascular disease, chronic neurological pathology (e.g., dementia, epilepsy, parkinsonism), mental retardation, and major psy. chiatric disorders. Subject sampling was stratified by 13 discontin. uous age classes (25 years $\pm 1,30$ years, . ., 85 years \pm 1 ) and sex. A total number of 3,921 persons were drawn from the register. After screening by the general practitioners, 187 were excluded because of present illness or psychosocial indications. The remaining 3,734 were invited by their practitioner to participate in the study; 2,340 were willing to participate and received the postal questionnaire. A total of 2,043 participants completed and returned the postal questionnaire in good order.

Due to missing data on the questions concerning subjective cognitive functioning, 95 persons were excluded leaving a total number of 1,958 participants (see below). There were slightly more women $(54 \%)$ than men in the sample. The age range was 24 to 86 years with a mean age of 53.1 years. Educational level was measured by a Dutch scoring system (de Bie, 1987) which consists of an 8-point scale, ranging from unfinished primary education (level 1) to university education (level 8). Mean educational level was 3.2 for the total group, but increasing age was associated with a lower level of education.

In the second phase of the cross-sectional study, a subsample of 420 persons from the postal survey sample was selected and were administered a series of cognitive tests. There was a considerable time lag of 3 to 12 months between filling in the postal questionnaire and cognitive testing. Approximately one third of the participants was tested within 3 to 6 months, one third within 7 to 8 months, and one third between 9 and 12 months. The subsample was again stratified for age (12 age classes, see above), sex, and two levels of occupational achievement to control for the effects of relevant cognitive performance predictors. The age range was 24 to 82 years (mean age 51.2 years) and the mean educational level was 3.5. Fifty-one percent of the sample was of the male sex.

\section{Measures}

\section{Subjective Cognitive Functioning}

'The subjects were asked to evaluate their present cognitive functioning by comparing it to that of people of their own age (Same Age 
scale) by aparing it to their level of cognitive functioning 5-10 years ago (Recent Past scale), and by comparing their present level with that when they were 25 years old (Early Adulthood scale). In each scale eight identical questions were asked which covered several cognitive functions. Four questions were related to attentional functions (the ability to concentrate, sustained and divided attention, and distractibility), two questions were related to decision making and planning ("executive functions"; Lezak, 1995), one question focused on memory, and one question concerned possible changes in mental speed. For example: "Compared to 5-1C years ago I find it ... to concentrate on things I see, hear, or read" (Recent Past scale: concentration). The subjects could rate possible changes on a 5-point scale ranging from much better or easier (score 1) to much worse or far more difficult (score 5); a score of 3 indicated no change or no difference. The subjects in the age range of 24-26 years did not fill in the Early Adulthood scale.

Missing data were handled in the following way. If only one of the eight questions of each scale was left blank, this question was assigned a score of 3 (the middle of the 5-point scale). Different number of persons still had missing data on one or more of the questions of each comparison scale (Early Adulthood scale: $n=178$; Same Age scale: $n=72$; Recent Past scale: $n=48$ ). We decided to include only those persons with complete data for the Recent Past and the Same Age scale. As a result of this criterion, 85 persons $(5 \%)$ of the original group of 2,043 were excluded from further analysis. There were 127 persons aged 24 to 26 who were asked not to fill in the Early Adulthood scale. From the remaining group of 1,831 persons aged 29 to 86 years, 143 still had missing values for the Early Adulthood scale, so that the number of persons for the Early Adulthood scale was 1688.

\section{Objective Cognitive Functioning}

A set of neuropsychological tests was administered which tapped memory and memory-related functions, attention, mental speed, and complex information processing.

The Motor Choice Reaction Test is a computer test that evaluates reaction times as a function of the complexity of task requirements (Houx \& Jolles, 1993). The task used here combines response selection with stimulus-response incompatibility. The variables of interest are the time needed for decision making and the actual movement time.

The Letter-Digit Modalities Test is a modification of the procedurally identical Symbol-Digit Modalities Test (Lezak, 1995). It is used as a measure of the speed of processing of general information, that is, the test is supposed to draw upon several (cognitive) processes 
such as visual perception, attention, and memory. - a two variables of interest are the number of correctly coded letter-digit combinations in 90 seconds on an oral and written administration.

The Concept Shifting Test is derived from the well-known Trail Making Test (Lezak, 1995), which is used to measure the ease of shifting between concepts. There are three task conditions: the subject has to cross out, in the proper order, 16 circles containing only digits (1 to 16; part A), letters (A to P; part B), or both (1-A-2-B, etc.; part $C)$. In the latter subtest, one has to shift between the concepts "digits" and "letters". The variables of interest are the times (seconds) needed to complete each subtest.

The Stroop Color-Word Test (Lezak, 1995) is a test of selective attention and interference susceptibility. The test involves three cards displaying 100 stimuli each: color names, colored patches, and color names printed in incongruously colored ink. For the last card, the color of the ink has to be named instead of the color name. This task is particularly sensitive to interference. The variables of interest are the times (seconds) needed to complete each card.

The Visual Verbal Learning Test (Brand \& Jolles, 1985) is a computerized, visual version of the Auditory Verbal Learning Test (Lezak, 1995). A set of 15 frequently used monosyllabic meaningful words is visually presented in a fixed order at a rate of one every two seconds in five consecutive trials. After each trial or presentation the subject is requested to recall as many words as possible with no restriction concerning the order of recall (immediate recall). Twenty minutes after the fifth presentation, the subject is again requested to recall as many words as he or she can remember (delayed recall). This test measures memory storage and retrieval of verbal information in episodic memory.

In the Fluency task, the subject is asked to name as many different animals and professions as possible in one minute. This test measures strategy-driven retrieval from semantic memory. The variables of interest are the number of correctly named animals and professions.

The multiple choice version of the Benton Visual Retention Test (Lezak, 1995) was used to evaluate short-term memory in the visual modality. The variable of interest is the number of correctly identified visual figures.

\section{Affective State and Subjective Health}

Feelings of depression were measured with the subscale Depression of the revised version of the Symptom Checklist (SCL-90; Derogatis, 1977; Dutch version: Arrindell \& Ettema, 1986). The SCL-90 is a multidimensional self-report inventory of current psychopathology. 
Items are ted on a 5-point scale. The subscale Depression contains 16 items which reflect symptoms of depression (score range 16-80). Subjective health was measured with the Dutch Inventory of Subjective Health (Dirken, 1967). The 21-item version administered in this study probes health complaints of a somatic and psychosomatic nature. The score range is $0-21$.

\section{Data Analysis}

Principal component analyses (PCA) were conducted on the three comparison scales to examine the coherence between the different cognitive functions that were tapped in the eight questions. Separate PCA were performed in a young and old sample to examine possible effects of age on the factor structure. In addition to the PCA, internal consistency estimates were calculated (Cronbach's alpha). Multiple regression analyses were conducted to examine the relation between age, sex, education, depression and subjective health and the scores on the three comparison scales. For each of the 15 cognitive test parameters $z$-scores were calculated based on the total population of tested subjects. Next, these $z$-scores were averaged to achieve an overall test performance score for each subject. Correlation analyses (zero-order, partial correlation) were performed to examine the relation between subjective and objective cognitive functioning. Because of the large sample sizes in this study, only probabilities of $1 \%$ or less were considered as significant, unless reported otherwise.

\section{RESULTS}

\section{Factor Structure}

A one-factor solution was found for all three comparison scales. This solution accounted for $46 \%$ of the variance in the Same Age scale (item loadings ranging from .44 to .77 ), $54 \%$ of the variance in the Recent Past scale (item loadings ranging from .49 to .80), and $56 \%$ of the variance in the Early Adulthood scale (item loadings ranging from .46 to .83). Internal consistency estimates for the Same Age scale, Recent Past scale, and the Early Adulthood scale were .82, .87, and .88 , respectively. To control for possible age differences in the factor structure of the three comparison scales, PCA and reliability analyses were performed separately for a young (all subjects younger than 51 years, $n=992$, mean age 38.7 years) and old subsample (all subjects older than 54 years, $n=966$, mean age 67.9 years). Again, a one-factor solution was found for the three scales in both groups. In 
the young group, the one-factor solution accounted ${ }^{r}$ " $46 \%$ of the variance on the Same Age scale (Cronbach's alpha . $\delta_{\sim,}, 54 \%$ on the Recent Past scale (alpha .88), and 52\% on the Early Adulthood scale (alpha .87). In the old group, these percentages were $46 \%, 48 \%$, and $53 \%$, respectively, with Cronbach's alphas of $.82, .83$, and .86 . These findings suggest that the factor structure of the three comparison scales is invariant over age.

\section{Effects of Age, Sex, Education, Depressión and Subjective Health}

On the basis of the results of the PCA, the eight questions of each comparison scale were combined into one comparison score. The mean scores for each scale for all the 13 age classes are presented in Table 1. The direction of the mean scores on the three comparison scales is shown in Figure 1. On the Same Age scale, the participants rated themselves as somewhat better than their "average" age-mates. However, when the participants had to rate their present cognitive functioning relative to their own past cognitive performance, an agerelated decline became apparent. Subjective decline in cognitive functioning was already noticed at the age of 50 and increased steadily thereafter, although in absolute terms these changes were of a rela-

TABLE 1 Mean Score and Standard Deviations per Comparison Scale as a Function of Age Class

\begin{tabular}{|c|c|c|c|c|c|c|c|c|}
\hline \multirow[b]{2}{*}{ Age class } & \multicolumn{3}{|c|}{$\begin{array}{l}\text { Same Age } \\
\text { scale }\end{array}$} & \multicolumn{2}{|c|}{$\begin{array}{l}\text { Recent Past } \\
\text { scale }\end{array}$} & \multicolumn{3}{|c|}{$\begin{array}{l}\text { Early Adulthood } \\
\text { scale }\end{array}$} \\
\hline & $n$ & $M$ & $S D$ & $M$ & $S D$ & $n$ & $M$ & $S D$ \\
\hline 25 years & 127 & 2.71 & 0.56 & 2.50 & 0.63 & - & - & - \\
\hline 30 years & 161 & 2.86 & 0.45 & 2.77 & 0.57 & 152 & 2.82 & 0.46 \\
\hline 35 years & 195 & 2.81 & 0.47 & 2.81 & 0.50 & 187 & 2.80 & 0.46 \\
\hline 40 years & 173 & 2.82 & 0.50 & 2.92 & 0.50 & 162 & 2.86 & 0.60 \\
\hline 45 years & 175 & 2.83 & 0.43 & 3.01 & 0.46 & 166 & 2.98 & 0.56 \\
\hline 50 years & 161 & 2.80 & 0.52 & 3.16 & 0.43 & 148 & 3.14 & 0.58 \\
\hline 55 years & 173 & 2.74 & 0.49 & 3.14 & 0.46 & 167 & 3.12 & 0.57 \\
\hline 60 years & 181 & 2.81 & 0.57 & 3.24 & 0.43 & 167 & 3.38 & 0.56 \\
\hline 65 years & 167 & 2.74 & 0.57 & 3.25 & 0.48 & 162 & 3.35 & 0.60 \\
\hline 70 years & 149 & 2.70 & 0.52 & 3.26 & 0.41 & 134 & 3.46 & 0.68 \\
\hline 75 years & 127 & 2.82 & 0.58 & 3.43 & 0.49 & 109 & 3.66 & 0.59 \\
\hline 80 years & 107 & 2.74 & 0.60 & 3.38 & 0.48 & 90 & 3.73 & 0.62 \\
\hline 85 years & 62 & 2.59 & 0.53 & 3.39 & 0.52 & 54 & 3.72 & 0.68 \\
\hline Total sample & 1958 & 2.78 & 0.52 & 3.06 & 0.56 & 1688 & 3.18 & 0.65 \\
\hline
\end{tabular}

Note. Minimum score is 1 (far more easy or better), maximum score is 5 (far more difficult or worse). 
More diffic

Worse

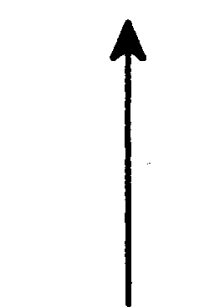

Unchanged

Same

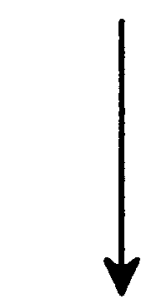

More easy

Better

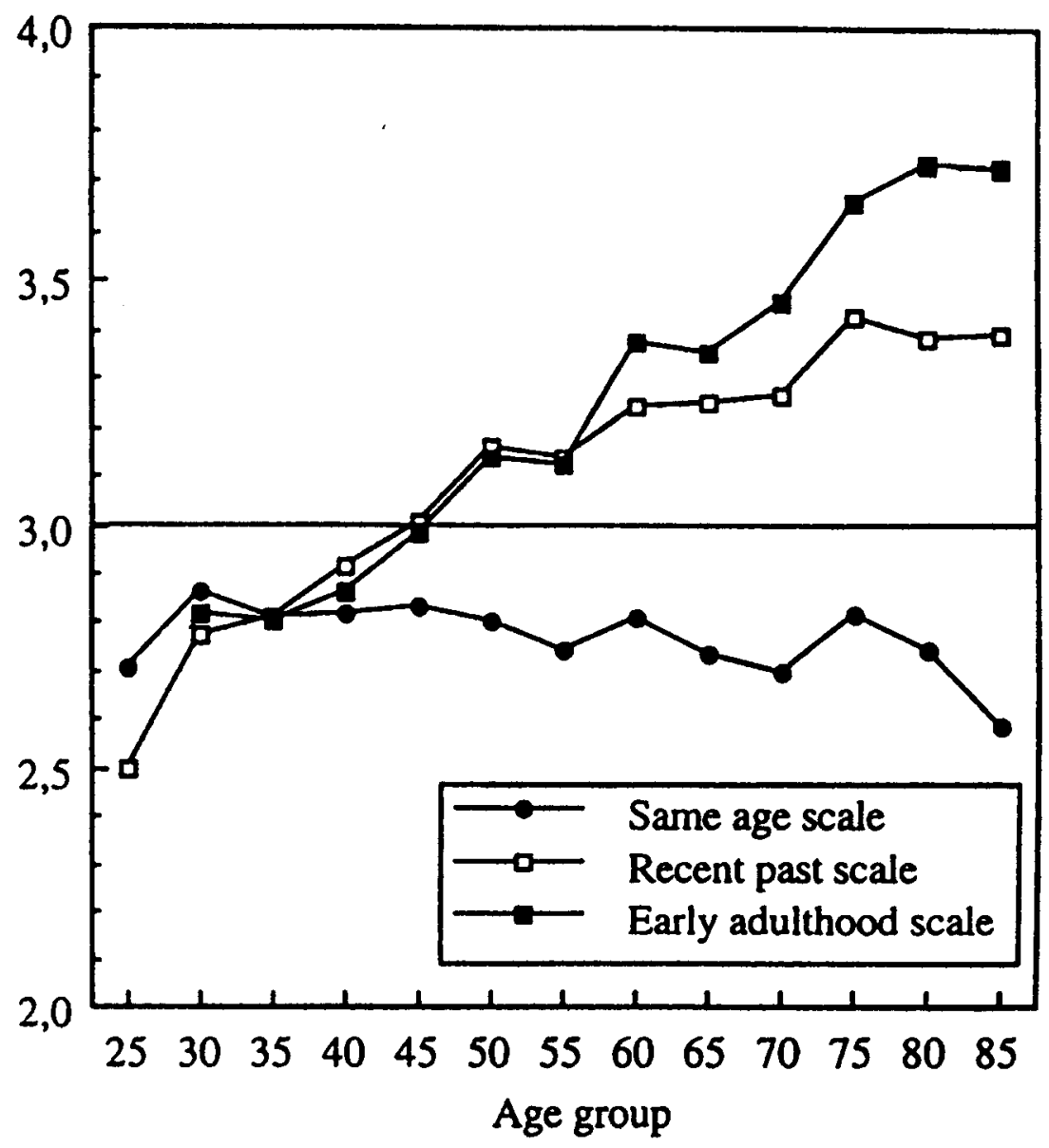

FIGURE 1 Subjective cognitive functioning as a function of age class.

tively small magnitude. As expected, this notion of decline was most prominent in the Early Adulthood scale. The younger groups (age classes 30,35 , and 40 years) judged their general cognitive functioning as being somewhat better than it was at the age of 25 years or 5-10 years ago. The steady increase in the decline was attenuated in the oldest age groups ( 80 and 85 years).

Multiple regression analyses were performed to examine the relation between the scores on the three comparison scales (dependent variables) and age, sex, education, depression, and subjective health (independent variables). All independent variables were entered and allowed to compete among themselves (stepwise forward). The criterion to enter was a correlation between the dependent and independent variable with a significance level of $p<.05$. Missing values for the depression and the subjective health questionnaire were replaced by the age-corrected scale means from the total sample. Separate regression analyses were performed for the subgroup with complete data on all predictor variables and the total group where total scores on the depression and subjective health questionnaire were replaced 
by the sample mean. Both methods yielded identic iesults. Therefore, only the analyses for the total group are presented here. The correlations between the variables in the regression and the results of the regression analyses are shown in Tables 2 and 3 . As expected, age accounted for a considerable amount of variance on the Recent Past scale $(19 \%)$ and the Early Adulthood scale (22\%). Subjective health

TABLE 2 Correlations Between the Three Scales of Sybjective Cognitive Functioning, Age, Education, Sex, Depression, and Subjective Health

\begin{tabular}{llrrrrrrr}
\hline & 1 & 2 & 3 & 4 & 5 & 6 & 7 & 8 \\
\hline 1. Same age & \multicolumn{1}{c}{ Sament } & & & & & & \\
2. Recent past & .44 & - & & & & & \\
3. Early adulthood & .39 & .80 & - & & & & \\
4. Age & -.06 & .44 & .47 & - & & & \\
5. Education & -.14 & -.24 & -.23 & -.37 & - & & \\
6. Sex & .13 & .07 & .05 & .00 & -.12 & - & & \\
7. Depression & .23 & .27 & .23 & .06 & -.14 & .17 & - & \\
8. Subjective health & .25 & .33 & .30 & .19 & -.28 & .14 & .51 & - \\
\hline
\end{tabular}

Note. Based on 1958 subjects, except for the Early Adulthood scale $(n=1688)$. For all correlations: $p<.01$ (one-tailed), except Early Adulthood scale and Sex $(p<.05)$, and Age and Sex (ns).

TABLE 3 Multiple Regression of Age, Sex, Education, Depression, and Subjective Health on the Three Scales of Subjective Cognitive Functioning

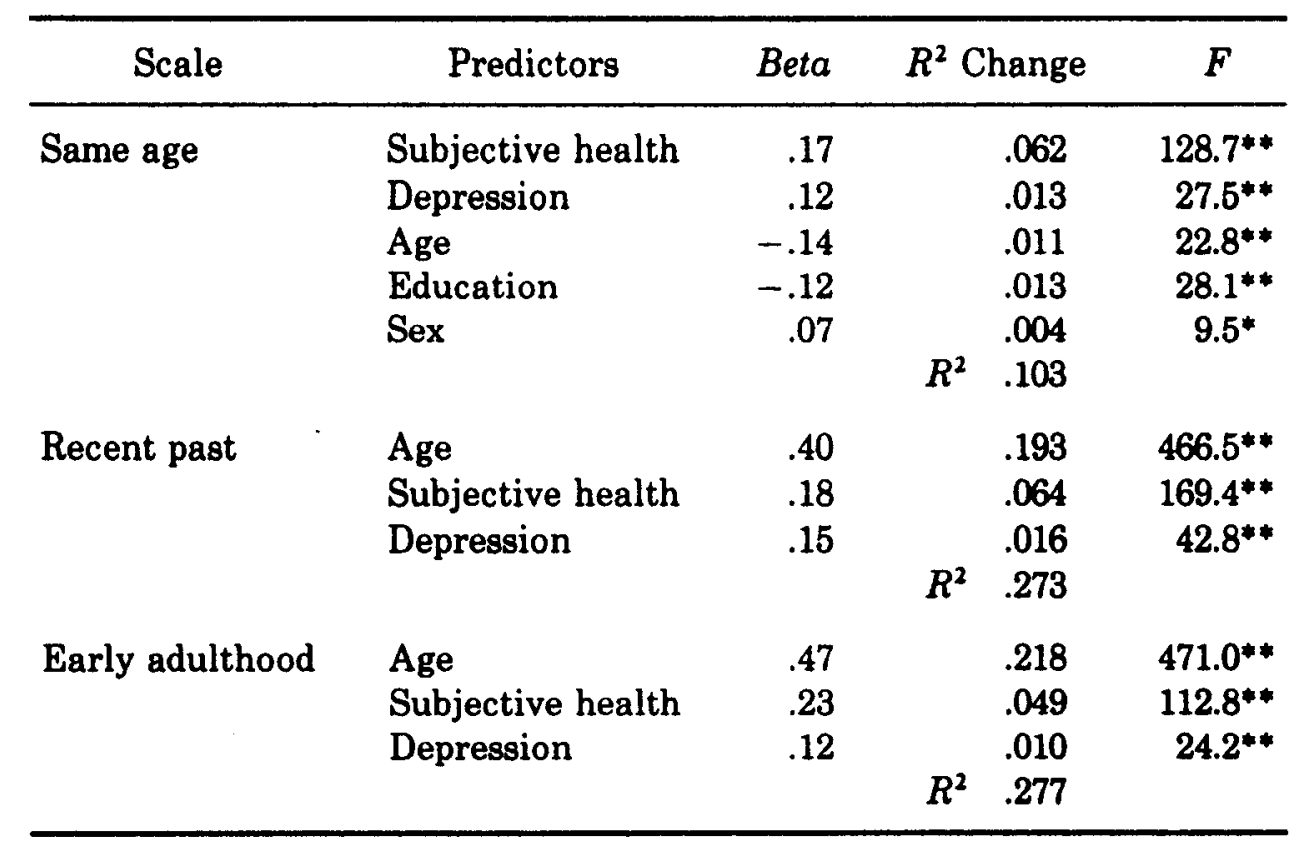

Note. Based on 1958 subjects, except for the Early Adulthood scale $(n=1688)$. Beta $=$ standardized regression coefficient in the final model.

${ }^{*} p<.01{ }^{* *} p<.001$. 
and depr on accounted for an additional $6 \%$ and $2 \%$ on the Recent Past scale and $5 \%$ and $1 \%$ for the Early Adulthood scale. Higher age, lower health ratings, and higher depression scores were related to higher scores on the two scales, indicating more decline in subjective cognitive functioning. Only $10 \%$ of the variance on the Same Age scale was explained by the set of predictors. The most substantial contribution was found for subjective health $(6 \%)$, followed by only small contributions of depression $(1 \%)$, age $(1 \%)$, education $(1 \%)$, and sex $(0.5 \%)$. Lower health ratings, higher depression scores, younger age, lower education, and being female were related to higher scores on the Same Age scale (lower cognitive functioning compared to agemates).

\section{Relation Between Subjective and Objective Cognitive Functioning}

Table 4 shows the correlations between the subjective cognitive scales, age, education, sex, subjective health, depression and overall test performance. As expected, the strongest correlations with test performance were found for age and education. Higher age and lower education were associated with lower overall test performance. There were significant negative zero-order correlations between the overall test performance and the Recent Past scale and Early Adulthood scale: more subjective decline was related to lower test performance. However, after controlling for the effects of age, education, sex, subjective health, and depression (partial correlation), the correlations dropped to zero or near zero (.00 for the Recent Past scale, .01 for the Early Adulthood scale, and - .08 for the Same Age scale).

\section{DISCUSSION}

This study mainly focused on the self-report of cognitive abilities in a large sample of normal and healthy persons covering a broad age range from young to very old. The main findings can be summarized as follows.

The results of the factor and reliability analyses suggest that the perceived change or decline in memory functioning with age is accompanied by a perceived change in attentional and executive functions as well. Cognitive aging, at least in the subjective domain, seems to be rather global in nature.

A decline in subjective cognitive functioning is already noticed at middle age (50 years) and steadily increases thereafter. This is in contrast with the general societal belief that the age-related decline in 


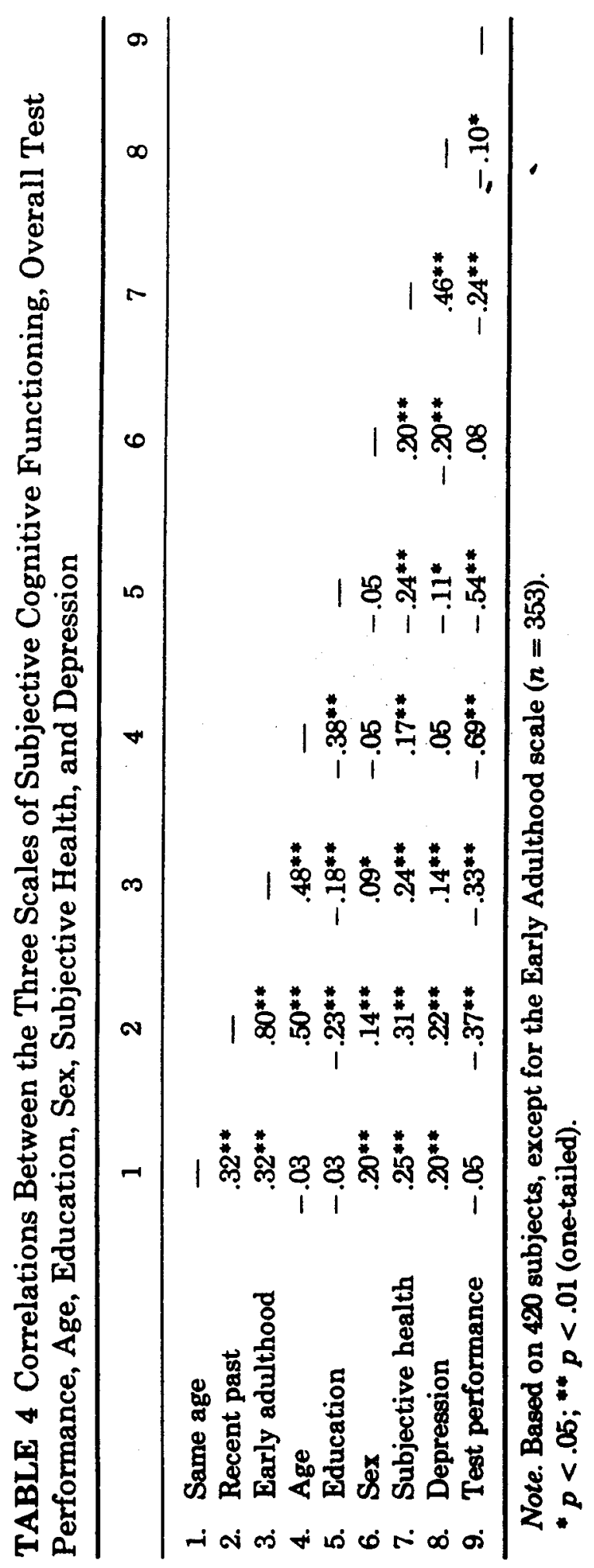


cognitive skills, especially memory, appears in the senium, i.e., after the age boundary of 65 years. At least as interesting is the finding that persons in the age range 25 to 40 years, believed that their present cognitive functioning was better than it was 5 to 10 years before. Although in an absolute sense, this perceived difference was small, it suggest that the "optimum" of subjective cognitive functioning occurs between 30 and 40 years instead between 20 and 30 years as one might have expected. The steady increase in perceived decline in cognitive functioning was attenuated in the oldest age groups ( 80 and 85 years), which might be explained as a "healthy survivor" effect. It is also possible that these elderly subjects were counting their blessings.

The question whether age differences are found in the self-report of cognitive functioning strongly depends on the type of comparison subjects have to make. Age differences in perceived cognitive functioning were only found when the subjects had to rate their present functioning in comparison to their functioning in the past. These effects were, as expected, strongest when the reference point was defined as 25 years. Only a very small age effect (less than $1 \%$ of explained variance) was found when subjects had to rate their present cognitive functioning to that of their age-mates. Overall, our participants rated themselves as somewhat better than their "average" age-mate, a phenomenon that is well known in social comparison studies as illusory superiority (Hoorens, 1993).

The perceived decline in cognitive functioning was more marked in the subjects with higher depression scores and lower ratings of subjective health, which is in line with previous studies on subjective memory. These effect modifications of subjective health and depression may in part be due to a general tendency to complain. The present data, however, do not allow to verify this possibility. Lower education was also related to a greater perceived decline. A similar relation was found by Arbuckle, Gold, and Andres (1986) and Cutler and Grams (1988). Gender either had no or only a marginal effect on subjective cognitive functioning.

As in many other studies, no correlation was found between subjective reports of cognitive functioning and actual performance on cognitive tests. The considerable time lag between the subjective reports and the administration of the cognitive tests, however, seriously limits the validity of this finding. No information is available on the stability of the subjective reports on cognitive functioning, subjective health, and depression. Moreover, we cannot rule out the possibility that changes (decline) in cognitive functioning have occurred during this time period, especially in the older subjects. 
Some studies have failed to show age differences on memory questionnaires that used absolute instead of relative measures of present memory functioning. To explain these findings, it has been suggested that with absolute measures, elderly subjects rate their present memory functioning to what they expect to be normal for their age (Cavanaugh, 1987; Hultsch et al., 1987). The absence of age differences on our scale, in which the participants yere explicitly asked to rate their present cognitive functioning compared to that of their age-mates, supports such an explanation. In other words, elderly people seem to have an adaptive attitude in their appraisal of cognitive functioning. This, however, does not necessarily imply that older subjects are satisfied about their cognitive functioning. After all, they still notice a decline in cognitive functioning. Thus, although their cognitive functioning may be at an expected level, it still may give rise to specific cognition-related problems in everyday life.

\section{REFERENCES}

Arbuckle, T. Y., Gold, D., \& Andres, D. (1986). Cognitive functioning of older people in relation to social and personality variables. Journal of Psychology and Aging, 1, 55-62.

Arrindell, W. A., \& Etterna, J. H. M. (1986). SCL-90. Een multidimensionele psychopathologie indicator [The SCL-90. A multidimensional instrument for the assessment of psychopathology]. Lisse, The Netherlands: Swets \& Zeitlinger.

Bolla, K. I., Lindgren, K. N., Bonaccorsy, C., \& Bleecker, M. L. (1991). Memory complaints in older adults. Fact or fiction? Archives of Neurology, 48, 61-64.

Brand, N., \& Jolles, J. (1985). Learning and retrieval rate of words presented auditorily and visually. The Journal of General Psychology, 112, 201-210.

Cavanaugh, J. C. (1987). Age differences in adults' self-reports of memory ability: It depends on how and what you ask. International Journal of Aging and Human Development, 24, 271-277.

Chaffin, R., \& Herrmann, D. J. (1983). Self report of memory abilities by old and young adults. Human Learning, 2, 17-28.

Crook, T. H., \& Larrabee, G. J. (1990). A self-rating scale for evaluating memory in everyday life. Psychology and Aging, 5, 48-57.

Cutler, S. J., \& Grams, A. E. (1988). Correlates of self-reported everyday memory problems. Journal of Gerontology: Social Sciences, 43, 82-90.

de Bie, S. E. (1987). Standaarduragen 1987-Voorstellen voor uniformering van vraagstellingen naar achtergrond-kenmerken en interviews [Toward a standardization of questions concerning demographic variables in population studies 2nd ed.]. Leiden: Leiden University Press.

Derogatis, L. R. (1977). SCL-90: Administration, scoring and procedures manual-I for the $R$ (evised) version. Baltimore: Johns Hopkins School of Medicine, Clinical Psychometrics Research Unit.

Dirken, J. M. (1967). Het meten van stress in industriële situaties [The measurement of stress in industrial situations]. Groningen, The Netherlands: Wolters.

Gilewski, M. J., \& Zelinski, E. M. (1986). Questionnaire assessment of memory complaints. In L. W. Poon (Ed.), Handbook for clinical memory assessment of older adults (pp. 93-107). Washington, DC: American Psychological Association. 
Hoorens, V. (1993). Self-enhancement and superiority biases in social comparison. In W. Stroebe \& M. Hewstone (Eds.), European review of social psychology, Volume 4 (pp. 113-139). Chichester: John Wiley \& Sons Ltd.

Houx, P. J., \& Jolles, J. (1993). Age-related decline of psychomotor speed: Effects of age, brain health, sex, and education. Perceptual and Motor Skills, 76, 195-211.

Hulicka, I. M. (1982). Memory functioning in late adulthood. In F. I. M. Craik \& S. Trehub (Eds.), Advances in the study of communication and affect: Aging and cognitive processes, Volume 8 (pp. 331-351). New York: Plenum Press.

Hultsch, D. F., Hertzog, C., \& Dixon, R. A. (1987). Age differences in metamemory: Resolving the inconsistencies. Canadian Journal of Psychology, 41, 193-208.

Jackson, J. L., Bogers, H., \& Kerstholt, J. (1988). Do memory aids aid the elderly in their day to day remembering? In M. M. Gruneberg, R. E. Morris, \& R. N. Sykes (Eds.), Practic aspects of memory: current research and issues: Clinical and educational implications (pp. 137-142). Chichester: John Wiley \& Sons.

Jolles, J., Houx, P. J., van Boxtel, M. P. J., \& Ponds, R. W. H. M. (Eds.) (1995). Maastricht Aging Study: Determinants of cognitive aging. Maastricht: Neuropsych Publishers.

Lezak, M. D. (1995). Neuropsychological assessment (3rd ed.). New York: Oxford University Press.

Lovelace, E. A. (1990). Aging and metacognitions concerning memory function. In E. A. Lovelace (Ed.), Aging and cognition: Mental processes, self awareness and interventions (pp. 157-188). North-Holland: Elsevier Science Publishers.

McMillan, T. M. (1984). Investigation of everyday memory in normal subjects using the subjective memory questionnaire (SMQ). Cortex, 20, 333-347.

Metsemakers, J. F. M., Höppener, P., Knottnerus, J. A., Kocken, R. J. J., \& Limonard, C. B. G. (1992). Computerized health information in the Netherlands: A registration network of family practices. British Journal of General Practice, 42, 102-106.

Rabbitt, P. (1982). Development of methods to measure changes in activities of daily living in the elderly. In S. Corkin, K. L. Davis, J. H. Growdon, E. Usdin, \& R. J. Wurtman (Eds.), Alzheimer's disease: A report of progress, Aging, Volume 19 (pp. 127-131). New York: Raven Press. 